\title{
Printed Triband Terminal Antenna
}

\author{
M. John*, M. J. Ammann* and R. Farrell ${ }^{\star \star}$
} Centre for Telecommunications Value-chain driven Research *School of Electronic \& Communications Engineering

Dublin Institute of Technology

**Electronic Engineering Department

National University of Ireland 


\title{
Printed Triband Terminal Antenna
}

\author{
M. John*, M. J. Ammann* and R. Farrell** \\ Centre for Telecommunications Value-chain driven Research \\ *School of Electronic \& Communications Engineering \\ Dublin Institute of Technology, Kevin Street, Dublin 8 \\ **Electronic Engineering Department \\ National University of Ireland \\ Maynooth, Co. Kildare, IRELAND
}

\begin{abstract}
This paper presents a printed triple-band multibranch monopole for use in modern wireless systems. The antenna is designed to operate in three bands which cover virtually all wireless channels. Parameters of the antenna geometry are varied and the effects of these variations on the impedance bandwidth are shown.
\end{abstract}

\section{Introduction}

The proliferation of wireless communications systems has placed enormous demands on antenna development. The requirements of antennas to be small, low-cost, have quasi-isotropic patterns over wide or multiple bandwidths and be integratable into radio circuitry are generally not always attainable. Many trade-offs are commonly made, juggling between parameters. The printed monopole is a suitable candidate with many variations proposed for dualband operation [1-4]. In this paper, a simple multibranch monopole printed on low-cost laminate is proposed as a triple-band terminal antenna, offering all of the above requirements to a greater degree.

\section{Antenna Geometry}

The triple band monopole is printed on one side of an FR4 substrate with a square groundplane located at the back. The FR4 properties are $(t=1.52 \mathrm{~mm}, 35 \mu \mathrm{m}$, $\operatorname{Dk}(2 \mathrm{GHz})=4.3, \tan \delta(2 \mathrm{GHz})=0.02)$. The dimensions of the substrate are $l=45 \mathrm{~mm}$ by $w=80 \mathrm{~mm}$ by $t=1.52 \mathrm{~mm}$. With $l_{g}=45 \mathrm{~m}$ the groundplane is square. The monopole is fed by a $w_{\digamma}=2 \mathrm{~mm}$ wide microstrip feedline. The dimensions of the antenna are $l_{m}=28 \mathrm{~mm}, l_{l}=15.8 \mathrm{~mm}, w_{F}=4 \mathrm{~mm}, l_{r}=10.6 \mathrm{~mm}$ and $w_{r}=4 \mathrm{~mm}$. The tap-off point is located $h_{l}=2 \mathrm{~mm}$ above the groundplane. These dimensions were obtained using a quasinewton-opimiser, optimising for the full coverage of three wireless bands. The antenna geometry is shown in Figure 1. 


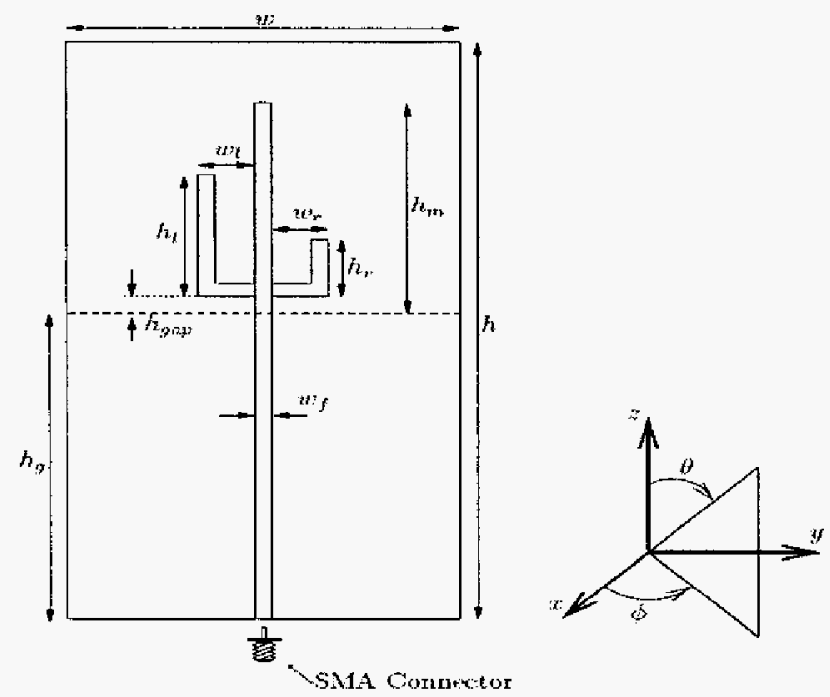

Figure 1: Geometry of the printed multibranch monopole

\section{Simulation and Measurement}

The antenna was modelled in CST Microwave Studio. The simulation with finiteintegration time-domain technique is in good agreement with measurement results. The measurements were made using a Rohde \& Schwarz ZVB network analyser. The simulated and measured return loss is shown in Figure 2. The three bands in which the return loss in greater than $10 \mathrm{~dB}$ are $1.8 \mathrm{GHz}$ to $2.7 \mathrm{GHz}, 3.4 \mathrm{GHz}$ to $3.7 \mathrm{GHz}$ and $4.8 \mathrm{GHz}$ to greater than $6 \mathrm{GHz}$. The lower band includes GSM1800/PCS1900, IMT2000 , the $2.45 \mathrm{GHz}$ ISM band, WLAN, IEEE $802.11 \mathrm{~b}, \mathrm{~g}$ and the IMT-2000 Extension band $(2.5-2.7 \mathrm{GHz})$. The middle band includes WiMax and WLL. The upper band covers IEEE $802.11 \mathrm{j}$, a, the US-NII and the $5.8 \mathrm{GHz}$ ISM band.

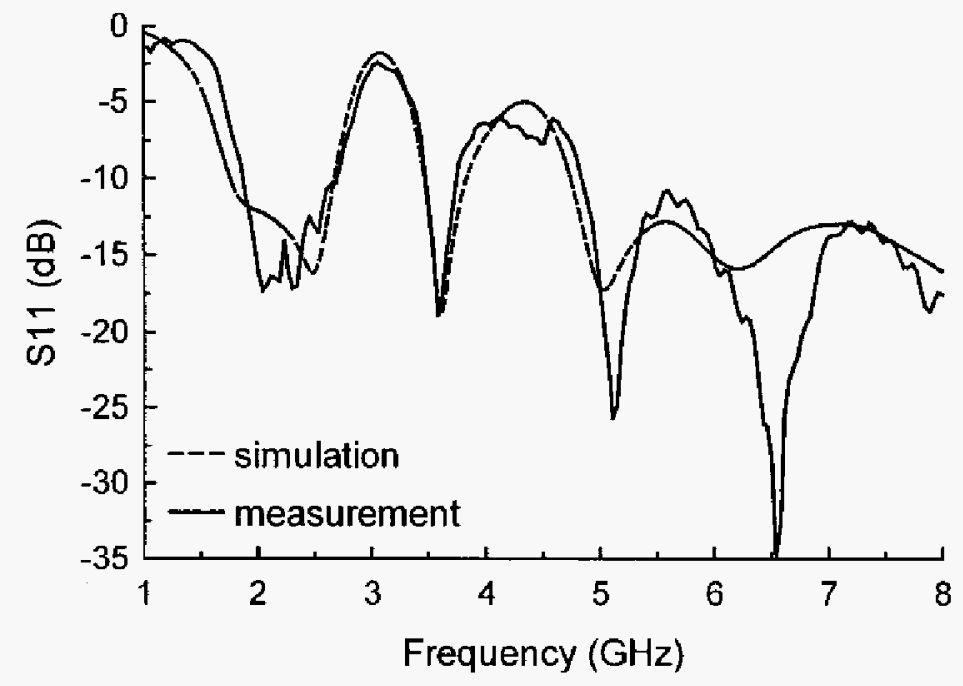

Figure 2: Measured and simulated return loss 
Due to FR4 substrate being used, total radiation efficiency drops from $89 \%$ at $2 \mathrm{GHz}$ to $69 \%$ at $6 \mathrm{GHz}$. This efficiency reduction must be considered above $6 \mathrm{GHz}$

\section{Parameter Dependence}

The dependence of impedance bandwidth on the height of the tap-off point $\left(h_{i}\right)$ was investigated for the three bands. Therefore, $h_{t}$ was varied from $0 \mathrm{~mm}$ to $4 \mathrm{~mm}$ and the return loss was measured. The bandwidth of the three bands is shown in Figure 3 . The upper and middle bands show maximum bandwidth for tap-off heights between $1.5 \mathrm{~mm}$ and $2.5 \mathrm{~mm}$. The lower band increases steadily with tap-off height.

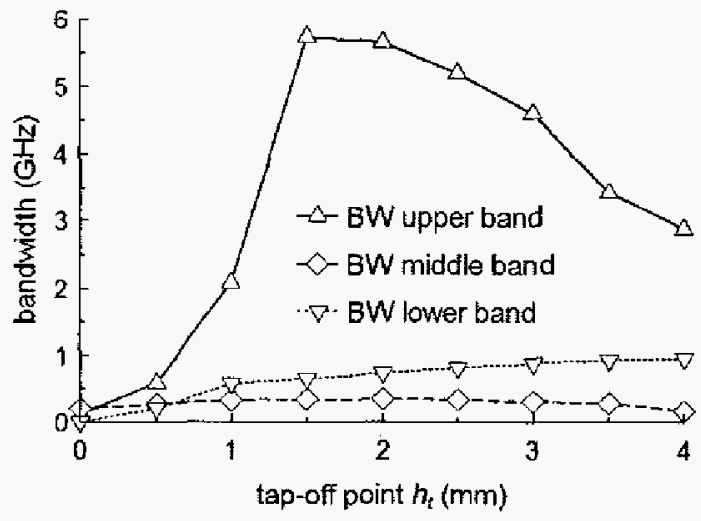

Figure 3. Impedance bandwidth dependence on tap-off point

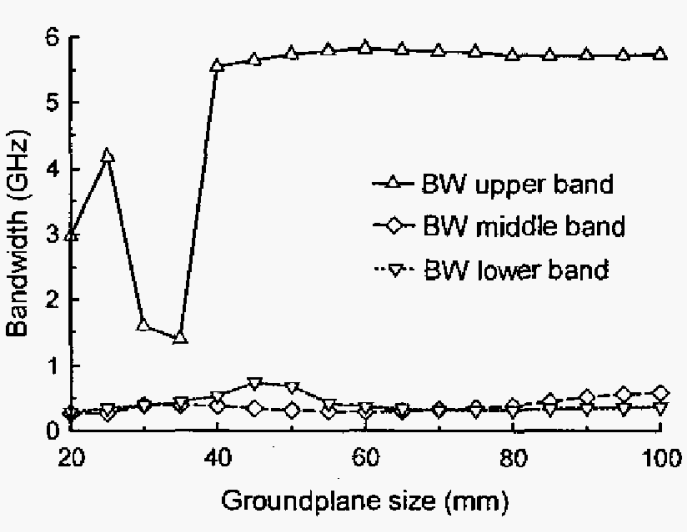

Figure 4. Impedance bandwidth dependence on groundplane size

The groundplane size was varied from $20 \mathrm{~mm}$ to $100 \mathrm{~mm}$ square. The bandwidth of all three bands is shown in Figure 4. The upper band shows maximum bandwidth for groundplane sizes above $40 \mathrm{~mm}$. The lower band has its optimum bandwidth from $40 \mathrm{~mm}$ to $50 \mathrm{~mm}$ groundplane size. The middle band shows very little dependence on groundplane size. It should be noted that the FR4 loss contributes significantly to antenna bandwidth at the upper band, but its contribution at the lower band is negligible. The bandwidth for the upper band for a tap-off point of $2.5 \mathrm{~mm}$ would be $3 \mathrm{GHz}$ instead of $5.5 \mathrm{GHz}$, if the laminate were low-loss.

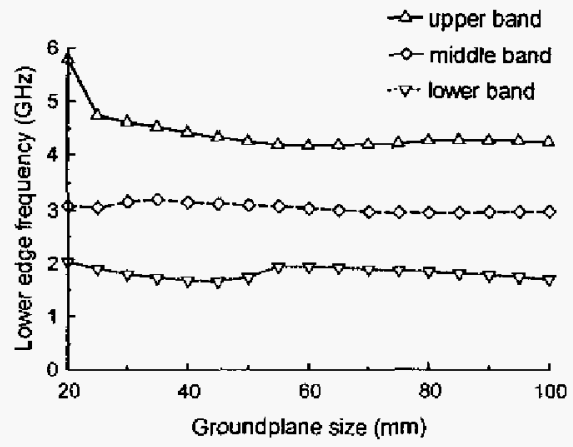

Figure 5. Lower edge frequency dependence on groundplane size 
When dealing with small antennas, it is sometimes useful to examine the lower edge frequency (LEF) dependence on groundplane size. The effect on the lower edge frequency of the three bands is shown in Figure 5. Standard deviations of the lower edge frequencies are $10 \%$ for the lower band, $7 \%$ for the middle band and $37 \%$ for the upper band ( $16 \%$ ignoring the first value $(20 \mathrm{~mm} \mathrm{GP})$ ). It can be seen that a GP size of $45 \mathrm{~mm}$ yields the lowest LEF for the first band.

\section{Radiation Patterns}

Simulated patterns are presented in Figure 6. The maximum gain is $3.0 \mathrm{dBi}$ at $2 \mathrm{GHz}$, $2.5 \mathrm{dBi}$ at $3.4 \mathrm{GHz}$ and $3.4 \mathrm{dBi}$ at $5.5 \mathrm{GHz}$.
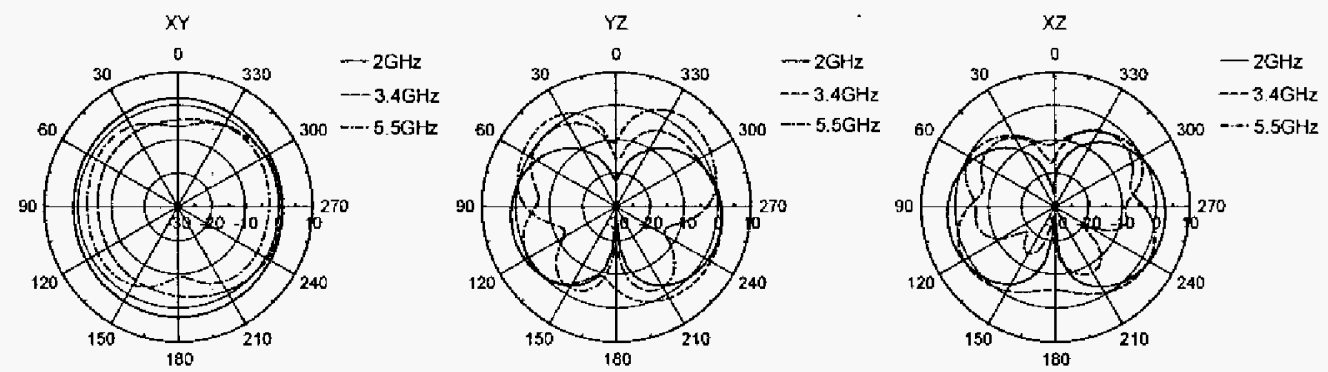

Figure 6: Radiation Patterns for the (xy), (yz) and (xz) planes at $2 \mathrm{GHz}, 3.4 \mathrm{GHz}$ and $5.5 \mathrm{GHz}$

\section{Conclusion}

A printed tripleband multibranch monopole was presented in this paper. It was investigated how the bandwidth depends on various parameters of the antenna geometry. The antenna was optimised to achieve optimum bandwidth in the desired frequency bands.

\section{Acknowledgements}

This work has been supported by the Science Foundation Ireland.

\section{References}

1. S. H Yeh and K. L Wong,

"Integrated F Shaped Monopole Antenna for 2.4/5.2 Dual-Band Operation,"

Microwave \& Optical Technology Letters, 2002, (34), 24-26.

2. John, M and Ammann, M. J,

The Effect Of Groundplane Size And Branch Off Point On The Performance Of The Printed

Multibranch Monopole

Loughborough Antennas \& Propagat. Conf. 2005, $189-192$.

3. W. C. Liu, W. R.Chen and C. M. Wu,

"Printed Double S-shaped Monopole Antenna for Wideband and Multiband Operation of Wireless Communications," IEE Proc. MAP. 2004, 151, (6), 473-476.

\section{D. Liu,}

"Branch Number and Height Effects on the Multi-Branch Dual-Band Monopole Antenna," IEEE APS

Simp Dig 2000, 1302-1305 
